\title{
High-Surface-Area, Emulsion-Templated Carbon Foams by Activation of polyHIPEs Derived from Pickering Emulsions
}

\author{
Robert T. Woodward ${ }^{1}$ * , François De Luca ${ }^{1}$, Aled D. Roberts ${ }^{2}$ and Alexander Bismarck ${ }^{3}$ \\ 1 Department of Chemical Engineering, Imperial College London, South Kensington Campus, \\ London SW7 2AZ, UK; f.de-luca13@imperial.ac.uk \\ 2 Department of Chemistry, University of Liverpool, Crown Street, Liverpool L69 7ZD, UK; \\ aleddeakin@gmail.com \\ 3 Polymer and Composite Engineering (PaCE) Group, Institute of Materials Chemistry \& Research, \\ Faculty of Chemistry, University of Vienna, Währingerstraße 42, Vienna 1090, Austria; \\ alexander.bismarck@univie.ac.at \\ * Correspondence: r.woodward@imperial.ac.uk; Tel.: +44-20-7589-5111 \\ Academic Editors: To Ngai and Jonathan Phillips \\ Received: 30 June 2016; Accepted: 9 September 2016; Published: 14 September 2016
}

\begin{abstract}
Carbon foams displaying hierarchical porosity and excellent surface areas of $>1400 \mathrm{~m}^{2} / \mathrm{g}$ can be produced by the activation of macroporous poly(divinylbenzene). Poly(divinylbenzene) was synthesized from the polymerization of the continuous, but minority, phase of a simple high internal phase Pickering emulsion. By the addition of $\mathrm{KOH}$, chemical activation of the materials is induced during carbonization, producing Pickering-emulsion-templated carbon foams, or carboHIPEs, with tailorable macropore diameters and surface areas almost triple that of those previously reported. The retention of the customizable, macroporous open-cell structure of the poly(divinylbenzene) precursor and the production of a large degree of microporosity during activation leads to tailorable carboHIPEs with excellent surface areas.
\end{abstract}

Keywords: carbon; polyHIPE; carboHIPE; Pickering emulsion; carbonization; microporous; emulsion template

\section{Introduction}

Carbonaceous materials possessing hierarchical porosity are desirable owing to a number of advantageous properties, one such example being the coupling of effective mass transfer through macropores and large surface areas derived from both meso- and micropores. High surface areas allow for a large degree of solid-liquid interactions, while effective mass transfer permits rapid access to this surface area throughout the material. More generally, carbonaceous materials are studied prolifically due to their relative chemical inertness and high thermal stability, which has resulted in their consideration as adsorbents [1] or catalyst supports [2], in gas sorption [3], and as electrodes in both Li-ion batteries [4] and double-layer capacitors [5].

The requirement for well-defined porosity within carbon structures has led to the utilization of a range of different precursor materials including carbides [6,7], synthetic organic polymers [8,9], and templated materials $[10,11]$. One attractive route to hierarchically porous carbon foams is via the carbonization of macroporous polymers templated from high internal phase emulsions (HIPEs). A HIPE is defined as an emulsion containing an internal phase that comprises $>74.05 \%$ of the total volume of the system, the maximum volume that uniform spheres can close pack without deformation [12]. Polymers are produced from these templates by the polymerization of the continuous, but minority, phase of a HIPE to produce a polyHIPE. Aside from the influence of phase volume 
ratio and the emulsification method, a great degree of control over the structural properties of a polyHIPE's macropores is possible simply by varying the choice of emulsion stabilizer in the initial HIPE template. HIPEs are commonly stabilized using standard molecular surfactants, which upon polymerization produce open-cell polyHIPEs, meaning that the polymers contain pore throats which connect the emulsion-templated macropores, producing a more permeable structure. On the other hand, particle-stabilized emulsions, also known as Pickering emulsions, are stabilized by larger particles irreversibly adsorbing at the interface of emulsion [13,14]. Upon polymerization of Pickering HIPEs, closed-cell polyHIPEs containing no pore throats and macropores with larger diameters than those of the surfactant systems are produced $[15,16]$. However, it was demonstrated by Wong et al. that open-cell polyHIPEs could be produced from Pickering HIPEs via the addition of a small amount of a standard molecular surfactant prior to polymerization, introducing pore throats into Pickering-HIPE derived polyHIPEs [17].

When a charable polyHIPE is produced, it can be used as a precursor to porous carbon foams, or carboHIPEs, which retain the emulsion-templated macroporosity of the polyHIPE while developing micro- and mesopores upon carbonization, creating hierarchical porosity. The production of carboHIPEs has been described in the literature from a wide variety of starting materials, some of which include sulfonated poly(styrene-co-divinylbenzene) [18,19], Kraft black liquor [20], lignin [21], tannins [22], and polyacrylonitrile [23]. Recently, we described the production of carboHIPEs from poly(divinylbenzene)HIPEs synthesized from simple Pickering water-in-divinylbenzene (DVB) HIPE templates [24]. Carbonization of these templates gave carboHIPEs in good yields, retaining the emulsion-templated porosity of the poly(DVB)HIPE precursor and producing surface areas of up to $500 \mathrm{~m}^{2} / \mathrm{g}$. Pickering HIPEs have also been used to create carboHIPEs by producing sacrificial molds in the form of mesoporous macrocellular silica foams [25]. These Si(HIPE)s were infiltrated with a carbon precursor, carbonized, and washed in HF to produce carboHIPEs with surface areas of up to $900 \mathrm{~m}^{2} / \mathrm{g}$.

In order to try to improve the surface area of carbonaceous materials in general, varying methods of activation have been employed. One method involves the addition of activating agents to charable materials to try to increase the surface area of the resulting carbon by chemical activation during heating. Another involves the carbonization of materials in atmospheres containing small amounts of $\mathrm{CO}_{2}$ or $\mathrm{H}_{2} \mathrm{O}$ in order to induce physical activation of the materials. The literature is rich with studies on activation processes, with one of the most popular involving the addition of the chemical activating agent, $\mathrm{KOH}$, to a material prior to carbonization [26]. Previous reports indicate that increases in porosity and surface area brought about by $\mathrm{KOH}$-activation is due to a number of factors including chemical activation by etching of the carbon framework, physical activation by the gasification of the carbon, and carbon lattice expansion by the production of metallic $\mathrm{K}$ throughout the carbon framework [26-29]. It has been demonstrated that the activation of templated mesoporous carbons with well-controlled pore-size distributions led to huge increases in both surface area and total pore volumes by the production of micropores [30,31].

Herein, we report the synthesis of high-surface-area, hierarchically porous carboHIPEs by $\mathrm{KOH}$-activation of poly(DVB) derived from Pickering HIPEs. The successful retention of emulsion-templated macroporosity during activation allows for carboHIPEs with almost triple the surface area of their non-activated (simply carbonized) equivalents. A combination of both silica particles and a small amount of standard molecular surfactant were used in order to create open-cell, charable structures. This increase in surface area, coupled with customizable macropore diameters, opens up opportunities to produce tailorable carboHIPEs with excellent surface areas. 


\section{Experimental}

\subsection{Materials}

Calcium chloride $\left(\mathrm{CaCl}_{2}\right)$, divinylbenzene (DVB, $80 \%$ containing inhibitor), azobisisobutyronitrile (AIBN), and potassium hydroxide $(\mathrm{KOH})$ were all purchased from Sigma-Aldrich (Dorset, $\mathrm{UK}$ ) and used as received. Hydrophobic silica particles (HDK grade H20) were kindly provided by Wacker Chemie (Bracknell, UK), and Hypermer 2296 was kindly provided by Croda (Leek, UK). Both products were used as received. Silver paint used for SEM imaging was purchased from Agar Scientific (Stansted, UK).

\subsection{Preparation of HIPEs and Subsequent poly(DVB)HIPEs}

The synthesis of poly(DVB)HIPEs from Pickering water-in-DVB HIPEs has been described previously [24]. For a typical formulation, hydrophobic silica particles $(120 \mathrm{mg}, 3 \mathrm{wt} \%)$ were added to DVB $(4 \mathrm{~mL})$, and the sample was shaken by hand for $\sim 5 \mathrm{~min}$ until the particles were well dispersed in the monomer. AIBN ( $1 \mathrm{~mol} \%$ with respect to the monomer, $47 \mathrm{mg}$ ) was then added and the mixture stirred using a vortex mixture ((VortexGenie 2, Scientific Industries, Bohemia, NY, USA), speed setting ' 3 ', equating to roughly $600 \mathrm{rpm})$ before an aqueous $\mathrm{CaCl}_{2}$ solution $(10 \mathrm{~g} / \mathrm{L}, 16 \mathrm{~mL})$ was added slowly over 20 min while still stirring using the vortex mixer at the same speed setting. After the addition of the aqueous phase was complete, the HIPE was stirred more vigorously (speed setting ' $10^{\prime}$, roughly $3000 \mathrm{rpm})$ for a further $5 \mathrm{~min}$ before the surfactant Hypermer 2296 ( $0.2 \mathrm{~mL}, 5 \mathrm{vol} \%$ ) (Croda, UK) was added with respect to the initial monomeric phase, after which the HIPE was gently agitated by hand for $10 \mathrm{~s}$. To create poly(DVB)HIPEs with smaller macropores, the HIPE was stirred at either $1000 \mathrm{rpm}$ or $3000 \mathrm{rpm}$ for $10 \mathrm{~s}$ at this point in the process, in place of gentle agitation by hand. HIPEs were then transferred into a $15 \mathrm{~mL}$ free standing polypropylene centrifuge (Falcon) tube (VWR, Radnor, PA, USA) and heated at $70{ }^{\circ} \mathrm{C}$ for $24 \mathrm{~h}$ in a convection oven to initiate polymerization. After polymerization, the Falcon tube containing the polyHIPE was cut into roughly $1 \mathrm{~cm}^{3}$ cylinders using a band saw before the polyHIPE was removed from the tubes and washed three times in an ethanol bath for a total of at least $6 \mathrm{~h}$. The cylinders were then dried in a vacuum oven at $110^{\circ} \mathrm{C}$ overnight.

\subsection{Preparation of carboHIPEs and Activated carboHIPEs}

Samples of poly(DVB)HIPE were prepared for either carbonization or carbonization in the presence of a chemical activator. All samples were weighed before heating to $800{ }^{\circ} \mathrm{C}$ under a $\mathrm{N}_{2}$ atmosphere at a ramp rate of $2{ }^{\circ} \mathrm{C} / \mathrm{min}$. Once $800{ }^{\circ} \mathrm{C}$ was reached, samples were held at this temperature for $1 \mathrm{~h}$ before the furnace was allowed to cool to room temperature overnight (remaining under a $\mathrm{N}_{2}$ atmosphere). Samples being prepared for chemical activation were also weighed before being soaked in an aqueous $\mathrm{KOH}$ solution (either a $10 \mathrm{wt} \%$ or a $30 \mathrm{wt} \%$ solution), after which they were carefully removed and placed in a convection oven at $70{ }^{\circ} \mathrm{C}$ to dry overnight. After drying, samples were weighed again to determine how much $\mathrm{KOH}$ was deposited before being placed in the furnace and carbonized using the same process as the non-activated carboHIPEs. When investigating tailored average macropore diameters in activated carboHIPEs, all poly(DVB)HIPEs were immersed in a $30 \mathrm{wt} \% \mathrm{KOH}$ solution before subsequent drying and carbonization as described above.

\subsection{Characterization}

Gas sorption analyses were performed on a Micromeritics 3Flex Surface Characterization Analyzer (Micromeritics, Atlanta, GA, USA) at $-196{ }^{\circ} \mathrm{C}$. Samples were degassed in situ under vacuum (around $0.0030 \mathrm{mbar}$ ) at $150{ }^{\circ} \mathrm{C}$ for at least $4 \mathrm{~h}$, prior to measurement. SEM images were either taken on a variable pressure SEM (JEOL JSM $5610 \mathrm{LV}(0.5-35 \mathrm{kV})$, Tokyo, Japan) or, in the case of the high-resolution SEM, images were taken using a high-resolution field emission gun SEM (FEGSEM (5 kV, InLens detector)) (Leo Gemini 1525 coupled with a SmartSEM software interface, Carl Zeiss NTS Ltd., Cambridge, UK). All polyHIPE samples were fixed on Al stubs (Agar Scientific Ltd., Stansted, 
UK) using carbon tape to attach samples securely. The stubs were then sputtered with chromium $(10 \mathrm{~nm})$ and, taking care not to contaminate the sample, a small amount of silver DAG paint was used to provide a conductive bridge between the carbon tape and the Al stub. Image analysis, such as measuring the average macropore diameter of polyHIPEs, was carried out using the image software ImageJ (version 1.48, National Institutes of Health, Bethesda, MD, USA) [32]. The percentage porosity $(\mathrm{P})$ was determined from both the envelope $\left(\rho_{e}\right)$ and skeletal density $\left(\rho_{s}\right)$ via the equation $\mathrm{P}=\left(1-\rho_{e} / \rho_{s}\right) \times 100 \%$.

\subsection{Research and Discussion}

Water-in-DVB emulsions were prepared using a combination of silica particles and standard molecular surfactants as stabilizers. The use of the Pickering emulsifiers was crucial as we previously demonstrated that poly(DVB)HIPEs derived from solely surfactant-stabilized HIPEs did not survive carbonization [24]. After curing the emulsions for $24 \mathrm{~h}$ at $70{ }^{\circ} \mathrm{C}$, all white poly(DVB)HIPEs were produced (Figure 1a), which displayed emulsion-templated macroporosity with an average diameter of $82 \mu \mathrm{m}$ (Table 1), in a similar range to other polyHIPEs produced from Pickering HIPEs [16,33]. As a mixed surfactant system was used, pore throats were created in the resulting poly(DVB)HIPE, producing the desired open-cell structure (Figure 1b). Poly(DVB)HIPEs were carbonized at $800{ }^{\circ} \mathrm{C}$ in an inert $\mathrm{N}_{2}$ atmosphere and yielded carbon foams, or carboHIPEs (Figure 1a). The carboHIPEs retained the cylindrical shape of poly(DVB)HIPE precursors well, albeit with a significant volume loss of between $73 \%$ and $76 \%$. The emulsion-templated macropores also survived carbonization to yield an open-cell carboHIPE, showing a decrease in their average diameter of $20 \mu \mathrm{m}$ to $62 \mu \mathrm{m}$. (Figure 1c).

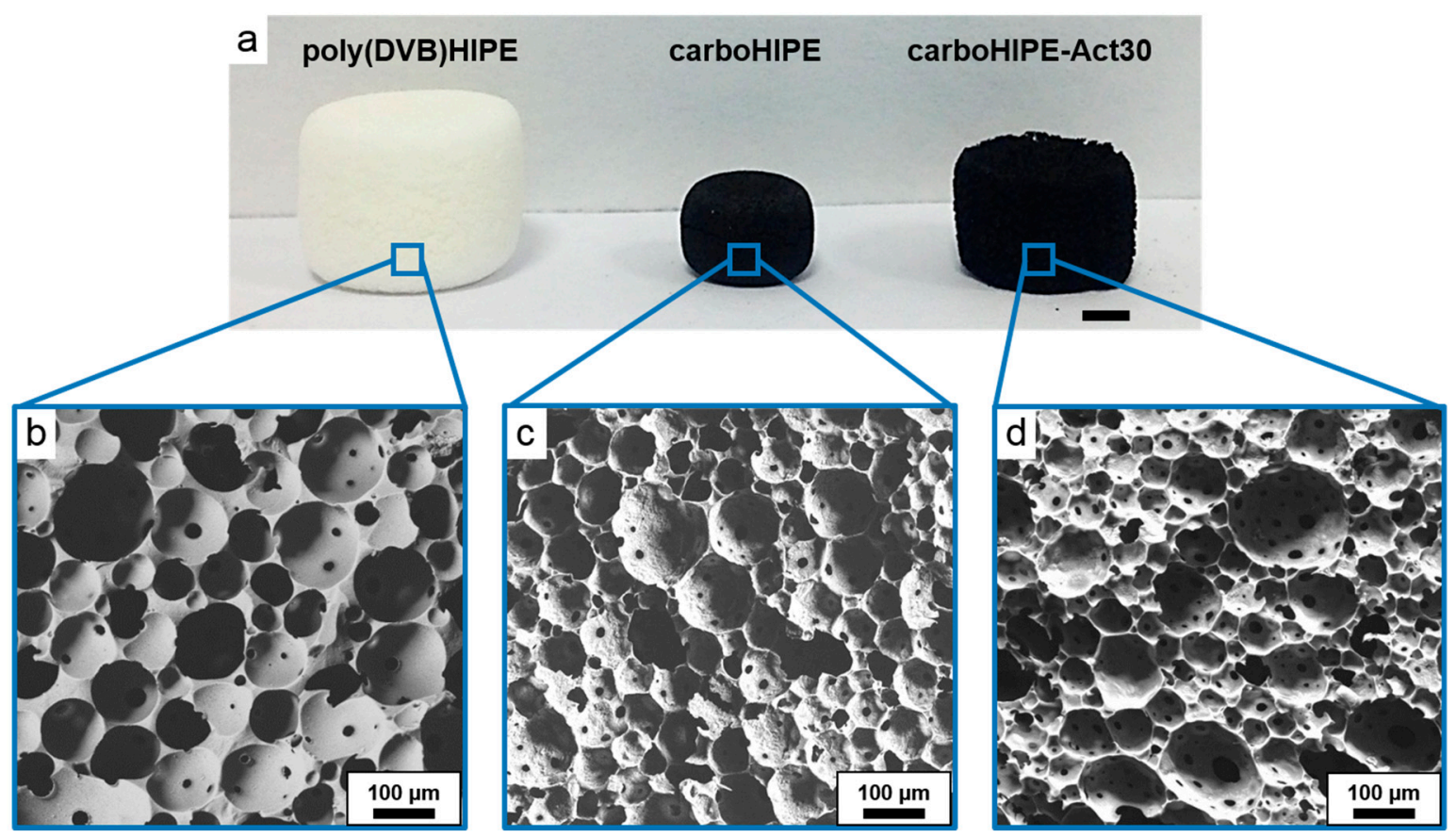

Figure 1. (a) Photograph of a poly(DVB)HIPE, carboHIPE, and a carboHIPE-Act30; (b-d) SEM images of a poly(DVB)HIPE, carboHIPE, and a carboHIPE-Act30, respectively. The scale bar in the photograph represents $2 \mathrm{~mm}$. 
Table 1. Macropore diameter, BET surface area, micropore volume, total pore volume, porosity, and char yield of a poly(DVB)HIPE, a carboHIPE, and activated carboHIPEs.

\begin{tabular}{|c|c|c|c|c|c|c|}
\hline Sample & $\begin{array}{c}\text { Average } \\
\text { Macropore } \\
\text { Diameter }(\mu \mathrm{m})^{\mathrm{a}}\end{array}$ & $\begin{array}{l}\text { Surface Area } \\
\left(\mathrm{m}^{2} / \mathrm{g}\right)^{\mathrm{b}}\end{array}$ & $\begin{array}{c}\text { Micropore } \\
\text { vol. }\left(\mathrm{cm}^{3} / \mathrm{g}\right)^{b}\end{array}$ & $\begin{array}{l}\text { Total Pore vol. } \\
\left(\mathrm{g} / \mathrm{cm}^{3}\right)^{b}\end{array}$ & $\begin{array}{l}\text { Porosity } \\
(\%)^{c}\end{array}$ & $\begin{array}{c}\text { Char Yield } \\
(\%)^{d}\end{array}$ \\
\hline poly(DVB)HIPE & $82 \pm 42$ & 8 & 0 & 0.021 & 86 & N/A \\
\hline carboHIPE & $62 \pm 28$ & 521 & 0.268 & 0.223 & 95 & 22 \\
\hline carboHIPE-Act10 & $72 \pm 26$ & 1123 & 0.432 & 0.572 & 97 & 13 \\
\hline carboHIPE-Act30 & $74 \pm 30$ & 1456 & 0.554 & 0.791 & 97 & 12 \\
\hline
\end{tabular}

${ }^{a}$ Measured using image analysis software; ${ }^{b}$ Calculated from $\mathrm{N}_{2}$ sorption isotherms at $77 \mathrm{~K} ;{ }^{\mathrm{c}}$ Calculated using both the skeletal and envelope density of monoliths and ${ }^{\mathrm{d}}$ Mass yield after carbonization, relative to original poly(DVB)HIPE.

Varying levels of activation of poly(DVB)HIPEs were achieved by submerging poly(DVB)HIPEs in $\mathrm{KOH}$ solution of varying concentrations for two hours under gentle agitation, prior to carbonization. The poly(DVB)HIPEs were then dried in an oven and carbonized in a similar procedure to the non-activated carboHIPEs. Activated materials will be denoted by the concentration of the $\mathrm{KOH}$ solution in which they were submerged; for example, in carboHIPE-Act10, the 'Act' refers to activation and ' 10 ' indicates that the poly(DVB)HIPE precursor was exposed to a $10 \mathrm{wt} \% \mathrm{KOH}$ solution. Activation of poly(DVB)HIPEs appeared to lead to slightly larger carboHIPEs than simple carbonization, with volume losses in activated materials ranging between $50 \%$ and $61 \%$ (Figure 1a), although this was admittedly hard to quantify in many samples due to the more irregular shapes and slightly more brittle nature of activated materials. The higher retention in volume may be due to the increased evolution of gas exerting outward pressure on structures during activation, or intercalated $\mathrm{K}$ in the carbon framework preventing further collapse. The emulsion-templated macropores were successfully retained during activation (Figure 1d) and showed a slightly reduced average macropore diameter of $74 \mu \mathrm{m}$ for carboHIPE-Act30, in good agreement with the reduced volume loss in comparison to simple carbonization in the absence of $\mathrm{KOH}$. In order to demonstrate the tailoring of macropore size in activated carboHIPEs, standard water-in-DVB HIPEs were stirred at varied rates after the addition of the Hypermer 2296 surfactant, prior to curing and activation. The samples were either gently agitated by hand (as is the case in the standard procedure), or stirred for $10 \mathrm{~s}$ at $1000 \mathrm{rpm}$ or $3000 \mathrm{rpm}$ using a vortex mixer. Average macropore diameters of $74 \pm 30 \mu \mathrm{m}$, $18 \pm 5 \mu \mathrm{m}$, and $11 \pm 4 \mu \mathrm{m}$ were obtained for the standard carboHIPE-Act30, and those stirred at 1000 and $3000 \mathrm{rpm}$, respectively (Figure 2), demonstrating controllable macropore size in activated carboHIPEs.
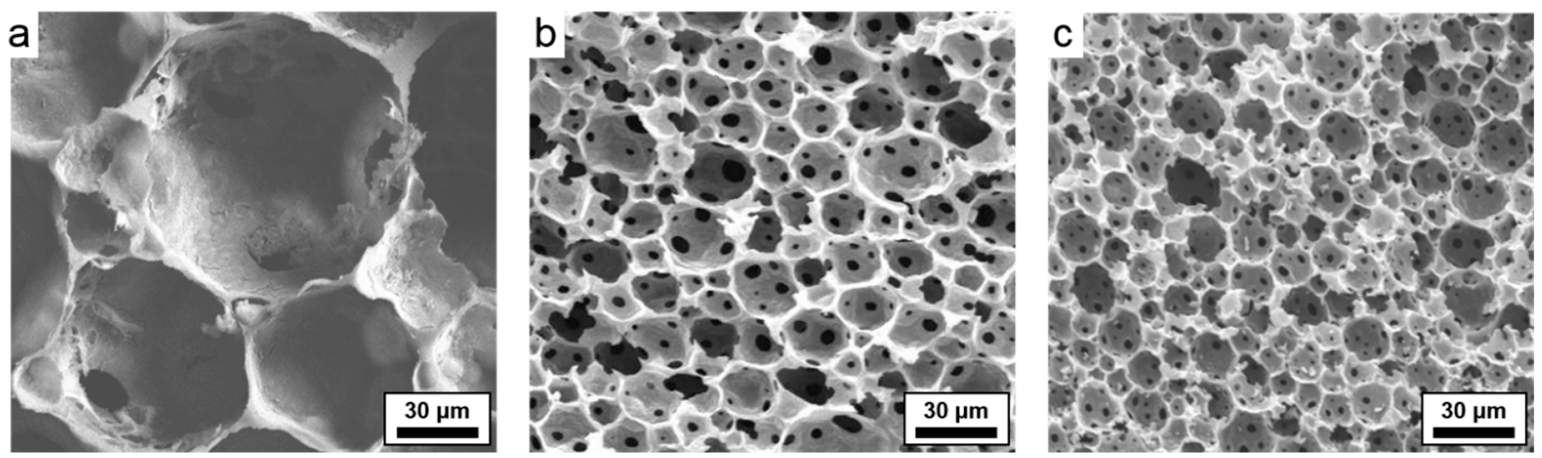

Figure 2. SEM images of various carboHIPE-Act30s with different average macropore diameters, produced by stirring the HIPEs at different speeds prior to polymerization. (a) Gently agitated by hand; (b) $1000 \mathrm{rpm}$ for $10 \mathrm{~s}$ on a vortex mixer; and (c) $3000 \mathrm{rpm}$ for $10 \mathrm{~s}$ on a vortex mixer.

Gas sorption analysis was performed on samples, applying the BET model for surface area measurements and determining the micropore volume using the t-plot method. The native 
poly(DVB)HIPE had a low surface area of $8 \mathrm{~m}^{2} / \mathrm{g}$ due to the presence of some mesoporosity within the structure $[24,34]$. All surface areas showed huge increases upon carbonization or activation, with nitrogen adsorption displaying a type I isotherm in all cases (Figure 3a), with a steep $\mathrm{N}_{2}$ uptake at low pressures, indicative of a predominantly microporous structure, as outlined by IUPAC classification [35]. The surface areas of carboHIPEs increased significantly with the addition of $\mathrm{KOH}$ prior to carbonization (Table 1), producing excellent surface areas of up to $1456 \mathrm{~m}^{2} / \mathrm{g}$ for carboHIPE-Act30. Both the total pore volume and the micropore volume also improved dramatically upon carbonization or activation, increasing from no notable microporosity in the poly(DVB)HIPE to an excellent micropore volume of $0.544 \mathrm{~cm}^{3} / \mathrm{g}$ and a total pore volume of $0.791 \mathrm{~cm}^{3} / \mathrm{g}$ in carboHIPE-Act30. Pore size distributions show this increase in micropore volume with a large peak at $\sim 5 \AA$ after both carbonization and activation, with activated samples appearing significantly more microporous (Figure 3b). By increasing the concentration of the initial $\mathrm{KOH}$ solution used to deposit the activating agent, both the surface area and the micropore volume could significantly increase (Figure 3, Table 1) without any significant structural damage occurring to the emulsion-templated macropores (Figure 1, Table 1).
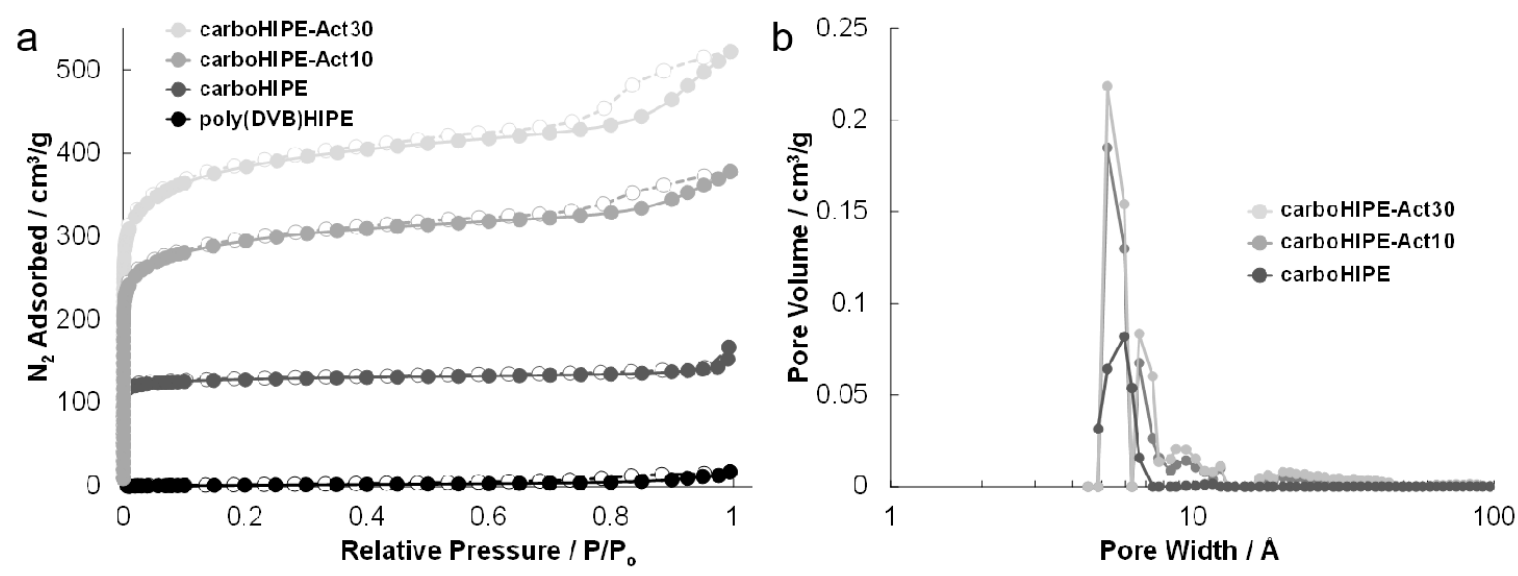

Figure 3. (a) $\mathrm{N}_{2}$ adsorption/desorption isotherms of all materials including a poly(DVB)HIPE, a carboHIPE, and carboHIPEs with varying degrees of activation (carboHIPE-Act10 and carboHIPE-Act30). Filled shapes show adsorption while empty shapes show desorption; (b) Non-local density functional theory pore size distribution for a carboHIPE, carboHIPE-Act10, and carboHIPE-Act30.

In order to further investigate the effect of the activating agent on the emulsion-templated structure and what may lead to the large increases in surface area, high magnification SEM was performed. When no activation agent was used during carbonization, the surface of the carboHIPE looked relatively smooth and unbroken with the exception of the pore throats in the images (Figure 4a,b). However, in carboHIPE-Act30, the surface was cracked and appeared more damaged after activation in comparison to carbonization with no $\mathrm{KOH}$ (Figure 4c,d). Considering the high magnification images of both the carboHIPE and carboHIPE-Act30, a much more porous structure is observed for the latter (Figure 4), with the visible pores mainly in the macropore region ( $>50 \mathrm{~nm}$ in diameter). This newly formed porous structure may allow better access to the increased amount of micropores throughout the structure, resulting in much higher surface areas.

Lastly, the degree of graphitization between samples was probed using Raman spectroscopy (Figure 5). It is clear from the spectra that carbonization/activation led to the formation of D and G modes (1350 $\mathrm{cm}^{-1}$ and $1582 \mathrm{~cm}^{-1}$, respectively) and the loss of the typical fine structure of the poly(DVB)HIPE in the Raman spectrum [36]. The formation of these broad D and G peaks is indicative of disordered graphitic carbonaceous structures [37], typical for carbonization at relatively low 
temperatures [38]. The D to G peak intensity ratio is around 0.9 for all samples, suggesting that the degree of graphitization is independent of the degree of activation in the carboHIPEs.
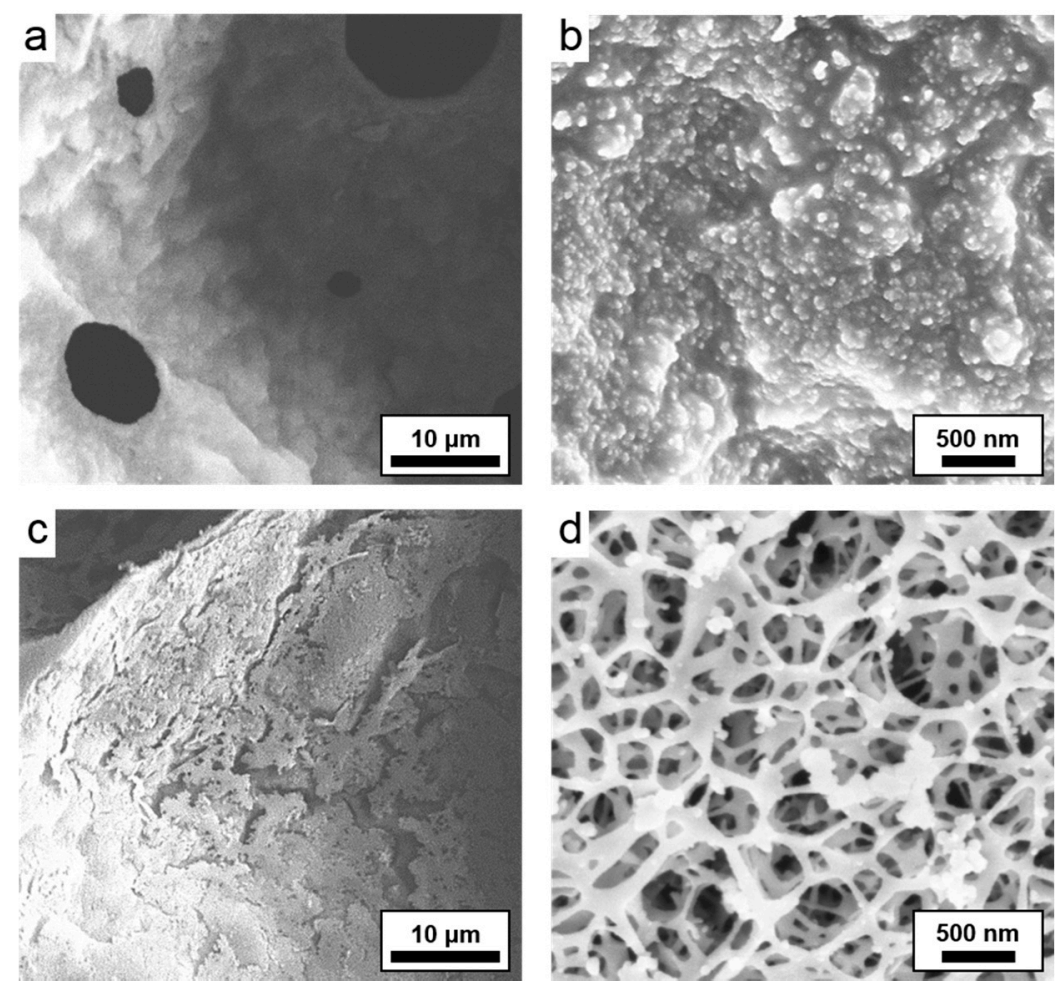

Figure 4. SEM images. (a,b) show a typical non-activated carboHIPE; and $(\mathbf{c}, \mathbf{d})$ show a typical activated carboHIPE-Act30.

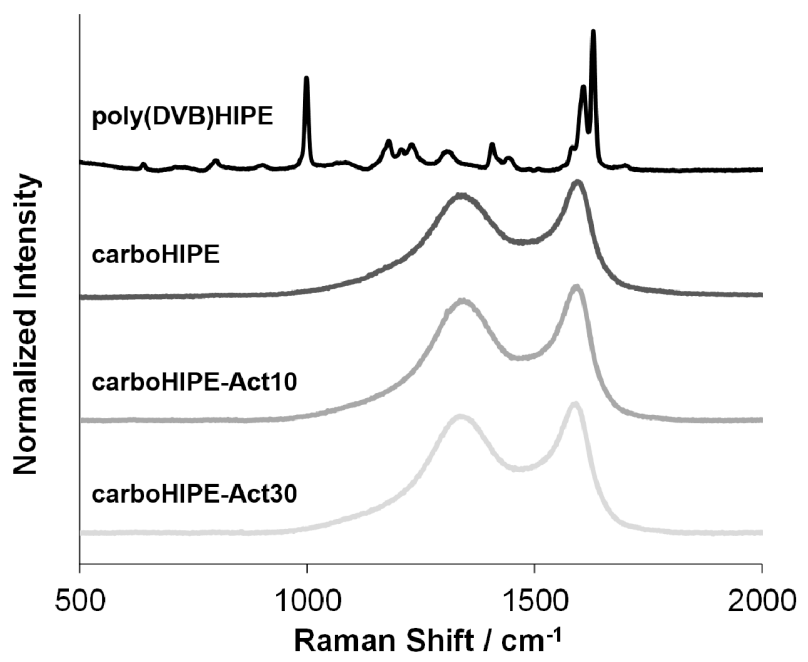

Figure 5. Raman spectroscopy of a poly(DVB)HIPE, a carboHIPE, and activated carboHIPEs.

\section{Conclusions}

By simple immersion and subsequent drying of Pickering-emulsion derived poly(DVB)HIPEs in inexpensive $\mathrm{KOH}$ solutions, carboHIPEs containing hierarchical porosity and surface areas of up to $1456 \mathrm{~m}^{2} / \mathrm{g}$ were easily produced upon carbonization. This addition of this simple step almost triples both the resulting surface area and micropore volume of carboHIPEs in comparison to poly(DVB)HIPEs 
carbonized in the presence of no activating agent. The degree of microporosity was controlled by varying the amount of $\mathrm{KOH}$ present during carbonization. The activation process was not detrimental to the emulsion-templated porosity of the poly(DVB)HIPEs, and it was demonstrated that the size of the macropores could also be dictated in activated carboHIPEs by controlling the amount of energy input after the addition of the standard surfactant. The retention of the macropores along with the production of large micropore volumes opens up potential for efficient mass transfer of electrolytes to the increased surface areas of these carbon foams, meaning they may have potential as novel monolithic electrodes in supercapacitor devices and will be investigated further. The tunable porosity of these materials on both the macro- and the micropore scale could also lead to their use as efficient adsorbents for the removal of organic pollutants, or as high surface area catalyst supports.

Acknowledgments: We wish to thank Ryan T. Luebke and Camille Petit (Imperial College London) for assistance with the gas sorption measurements shown. We also wish to thank David B. Anthony (Imperial College London) for assistance with Raman spectroscopy. We gratefully acknowledge funding from the UK Engineering and Physical Sciences Research Council (EPSRC) through the projects "graphene 3D networks" (EP/K01658X/1) and "nanoporous materials" (EP/J014974/1). The authors declare no conflict of interest.

Author Contributions: Robert T. Woodward and Alexander Bismarck conceived and designed the experiments; Robert T. Woodward performed the experiments and analysis; François De Luca contributed the high magnification SEM analysis; Aled D. Roberts devised and optimized the activation method and Robert T. Woodward wrote the paper.

Conflicts of Interest: The authors declare no conflict of interest.

\section{References}

1. Mohan, D.; Sarswat, A.; Ok, Y.S.; Pittman, C.U.J. Organic and inorganic contaminants removal from water with biochar, a renewable, low cost and sustainable adsorbent-A critical review. Bioresour. Technol. 2014, 160, 191-202. [CrossRef] [PubMed]

2. Wildgoose, G.G.; Banks, C.E.; Compton, R.G. Metal nanopartictes and related materials supported on carbon nanotubes: Methods and applications. Small 2006, 2, 182-193. [CrossRef] [PubMed]

3. Kemp, K.C.; Seema, H.; Saleh, M.; Le, N.H.; Mahesh, K.; Chandra, V.; Kim, K.S. Environmental applications using graphene composites: Water remediation and gas adsorption. Nanoscale 2013, 5, 3149-3171. [CrossRef] [PubMed]

4. Roberts, A.D.; Li, X.; Zhang, H.F. Porous carbon spheres and monoliths: Morphology control, pore size tuning and their applications as Li-ion battery anode materials. Chem. Soc. Rev. 2014, 43, 4341-4356. [CrossRef] [PubMed]

5. Sevilla, M.; Mokaya, R. Energy storage applications of activated carbons: Supercapacitors and hydrogen storage. Energy Environ. Sci. 2014, 7, 1250-1280. [CrossRef]

6. Gogotsi, Y.; Nikitin, A.; Ye, H.H.; Zhou, W.; Fischer, J.E.; Yi, B.; Foley, H.C.; Barsoum, M.W. Nanoporous carbide-derived carbon with tunable pore size. Nat. Mater. 2003, 2, 591-594. [CrossRef] [PubMed]

7. Yushin, G.; Dash, R.; Jagiello, J.; Fischer, J.E.; Gogotsi, Y. Carbide-derived carbons: Effect of pore size on hydrogen uptake and heat of adsorption. Adv. Funct. Mater. 2006, 16, 2288-2293. [CrossRef]

8. Meng, Y.; Gu, D.; Zhang, F.Q.; Shi, Y.F.; Cheng, L.; Feng, D.; Wu, Z.; Chen, Z.; Wan, Y.; Stein, A.; et al. A family of highly ordered mesoporous polymer resin and carbon structures from organic-organic self-assembly. Chem. Mater. 2006, 18, 4447-4464. [CrossRef]

9. Bear, J.C.; McGettrick, J.D.; Parkin, I.P.; Dunnill, C.W.; Hasell, T. Porous carbons from inverse vulcanized polymers. Microporous Mesoporous Mater. 2016, 232, 189-195. [CrossRef]

10. Yoon, S.B.; Kim, J.Y.; Yu, J.S. Synthesis of highly ordered nanoporous carbon molecular sieves from silylated MCM-48 using divinylbenzene as precursor. Chem. Commun. 2001. [CrossRef]

11. Lu, A.H.; Schuth, F. Nanocasting: A versatile strategy for creating nanostructured porous materials. Adv. Mater. 2006, 18, 1793-1805. [CrossRef]

12. Cameron, N.R.; Sherrington, D.C. High internal phase emulsions (HIPEs)—Structure, properties and use in polymer preparation. In Biopolymers Liquid Crystalline Polymers Phase Emulsion; Springer: Berlin/Heidelberg, Germany, 1996; pp. 163-214.

13. Pickering, S.U. CXCVI.-Emulsions. J. Chem. Soc. Trans. 1907, 91, 2001-2021. [CrossRef] 
14. Binks, B.P.; Lumsdon, S.O. Influence of particle wettability on the type and stability of surfactant-free emulsions. Langmuir 2000, 16, 8622-8631. [CrossRef]

15. Menner, A.; Verdejo, R.; Shaffer, M.; Bismarck, A. Particle-stabilized surfactant-free medium internal phase emulsions as templates for porous nanocomposite materials: Poly-pickering-foams. Langmuir 2007, 23, 2398-2403. [CrossRef] [PubMed]

16. Ikem, V.O.; Menner, A.; Bismarck, A. High Internal Phase Emulsions Stabilized Solely by Functionalized Silica Particles. Angew. Chem. Int. Ed. 2008, 47, 8277-8279. [CrossRef] [PubMed]

17. Wong, L.L.C.; Ikem, V.O.; Menner, A.; Bismarck, A. Macroporous Polymers with Hierarchical Pore Structure from Emulsion Templates Stabilised by Both Particles and Surfactants. Macromol. Rapid Commun. 2011, 32, 1563-1568. [CrossRef] [PubMed]

18. Wang, D.; Smith, N.L.; Budd, P.M. Polymerization and carbonization of high internal phase emulsions. Polym. Int. 2005, 54, 297-303. [CrossRef]

19. Asfaw, H.D.; Younesi, R.; Valvo, M.; Maibach, J.; Ångström, J.; Tai, C.-W.; Bacsik, Z.; Sahlberg, M.; Nyholm, L.; Edström, K. Boosting the thermal stability of emulsion-templated polymers via sulfonation: An efficient synthetic route to hierarchically porous carbon foams. Chem. Sel. 2016, 1, 784-792. [CrossRef]

20. Foulet, A.; Birot, M.; Backov, R.; Sonnemann, G.; Deleuze, H. Preparation of hierarchical porous carbonaceous foams from Kraft black liquor. Mater. Today Commun. 2016, 7, 108-116. [CrossRef]

21. Ungureanu, S.; Sigaud, G.; Vignoles, G.L.; Lorrette, C.; Birot, M.; Deleuze, H.; Backov, R. First Biosourced Monolithic Macroporous SiC/C Composite Foams (Bio-SiC/C(HIPE)) Bearing Unprecedented Heat Transport Properties. Adv. Eng. Mater. 2013, 15, 893-902. [CrossRef]

22. Szczurek, A.; Fierro, V.; Pizzi, A.; Celzard, A. Emulsion-templated porous carbon monoliths derived from tannins. Carbon 2014, 74, 352-362. [CrossRef]

23. Cohen, N.; Silverstein, M.S. Synthesis of emulsion-templated porous polyacrylonitrile and its pyrolysis to porous carbon monoliths. Polymer 2011, 52, 282-287. [CrossRef]

24. Woodward, R.T.; Fam, D.W.H.; Anthony, D.B.; Hong, J.; McDonald, T.O.; Petit, C.; Shaffer, M.S.P.; Bismarck, A. Hierarchically porous carbon foams from pickering high internal phase emulsions. Carbon 2016, 101, $253-260$. [CrossRef]

25. Ungureanu, S.; Birot, M.; Deleuze, H.; Schmitt, V.; Mano, N.; Backov, R. Triple hierarchical micro-meso-macroporous carbonaceous foams bearing highly monodisperse macroporosity. Carbon 2015, 91, 311-320. [CrossRef]

26. Wang, J.C.; Kaskel, S. KOH activation of carbon-based materials for energy storage. J. Mater. Chem. 2012, 22, 23710-23725. [CrossRef]

27. Romanos, J.; Beckner, M.; Rash, T.; Firlej, L.; Kuchta, B.; Yu, P.; Suppes, G.; Wexler, C.; Pfeifer, P. Nanospace engineering of $\mathrm{KOH}$ activated carbon. Nanotechnology 2012, 23. [CrossRef] [PubMed]

28. Wang, H.L.; Gao, Q.M.; Hu, J. High Hydrogen Storage Capacity of Porous Carbons Prepared by Using Activated Carbon. J. Am. Chem. Soc. 2009, 131, 7016-7022. [CrossRef] [PubMed]

29. Lozano-Castello, D.; Calo, J.M.; Cazorla-Amoros, D.; Linares-Solano, A. Carbon activation with $\mathrm{KOH}$ as explored by temperature programmed techniques, and the effects of hydrogen. Carbon 2007, 45, 2529-2536. [CrossRef]

30. Jin, J.; Tanaka, S.; Egashira, Y.; Nishiyama, N. KOH activation of ordered mesoporous carbons prepared by a soft-templating method and their enhanced electrochemical properties. Carbon 2010, 48, 1985-1989. [CrossRef]

31. Xing, W.; Huang, C.C.; Zhuo, S.P.; Yuan, X.; Wang, G.Q.; Hulicova-Jurcakova, D.; Yan, Z.F.; Lu, G.Q. Hierarchical porous carbons with high performance for supercapacitor electrodes. Carbon 2009, 47, 1715-1722. [CrossRef]

32. Schneider, C.A.; Rasband, W.S.; Eliceiri, K.W. NIH Image to ImageJ: 25 years of image analysis. Nat. Methods 2012, 9, 671-675. [CrossRef] [PubMed]

33. Menner, A.; Ikem, V.; Salgueiro, M.; Shaffer, M.S.P.; Bismarck, A. High internal phase emulsion templates solely stabilised by functionalised titania nanoparticles. Chem. Commun. 2007, 43, 4274-4276. [CrossRef]

34. Hainey, P.; Huxham, I.M.; Rowatt, B.; Sherrington, D.C.; Tetley, L. Synthesis and ultrastructural studies of styrene divinylbenzene polyhipe polymers. Macromolecules 1991, 24, 117-121. [CrossRef] 
35. Sing, K.S.W.; Everett, D.H.; Haul, R.A.W.; Moscou, L.; Pierotti, R.A.; Rouquerol, J.; Siemieniewska, T. Reporting physisorption data for gas solid systems with special reference to the determination of surface-area and porosity (recommendations 1984). Pure Appl. Chem. 1985, 57, 603-619. [CrossRef]

36. Stokr, J.; Schneider, B.; Frydrychova, A.; Coupek, J. Composition analysis of crosslinked styrene-ethylene dimethacrylate and styrene-divinylbenzene copolymers by raman-spectroscopy. J. Appl. Polym. Sci. 1979, 23, 3553-3561. [CrossRef]

37. Ferrari, A.C.; Robertson, J. Interpretation of Raman spectra of disordered and amorphous carbon. Phys. Rev. B 2000, 61, 14095-14107. [CrossRef]

38. Li, J.; Su, S.; Zhou, L.; Abbot, A.M.; Ye, H. Dielectric transition of polyacrylonitrile derived carbon nanofibers. Mater. Res. Express 2014, 1. [CrossRef]

(C) 2016 by the authors; licensee MDPI, Basel, Switzerland. This article is an open access article distributed under the terms and conditions of the Creative Commons Attribution (CC-BY) license (http://creativecommons.org/licenses/by/4.0/). 